\title{
Microscopy, is that an Effective Diagnostic Tool for Bacterial Vaginosis?
}

\author{
Rajesh Tile $^{1}$, Nisarga B. Kunte ${ }^{2}$, Nagarkar Rajhans Kishanrao ${ }^{3 *}$, \\ Supriya Jamkhandi ${ }^{1}$ and K. Parandekar Prashant ${ }^{3}$ \\ ${ }^{1}$ Department of Obstetrics and Gynecology, ESIC Medical College, Gulbarga, India \\ ${ }^{2}$ ICMR, India \\ ${ }^{3}$ Department of Microbiology, ESIC Medical College, Gulbarga, India \\ *Corresponding author
}

\section{Keywords}

Bacterial vaginosis (BV), Antenatal clinic, Nugent score

Article Info

Accepted:

04 May 2019

Available Online:

10 June 2019

\section{A B S T R A C T}

Bacterial Vaginosis (BV) is a shift or disturbance in balance of vaginal microflora, the normal vaginal microflora consisting of Lactobacillus is replaced by over growth of other commensal bacteria. Other characteristic of BV is increase in vaginal $\mathrm{pH}$. Clinically BV presents as increased thin homogenous vaginal discharge with or without burning micturation and itching. It is an extremely common health problem in women with sexually transmitted infections, pregnant women and women attending Gynecology clinics. Outcome of BV infection in pregnancy is low birth weight (LBW) infants and preterm births which is preventable. There are different methods to diagnose BV but microscopy is cost effective and easy. Aim of our study was to know the prevalence of BV in our study population and compare the diagnostic efficacy of two different microscopic methods. It was a prospective, cross sectional study with purposive sampling. Two swabs of vaginal discharge from posterior fornix were collected and processed using Amsel's criteria and Nugent score. In this study prevalence of BV was $16 \%$. Amsel's criterion is $15.38 \%$ sensitive and $88.52 \%$ specific whereas Nugent score method is $23.08 \%$ sensitive and $88.52 \%$ specific. Hence Nugent scoring is more effective and reliable method in comparison to Amsel's criteria. Clinical and microbiological investigations should be done in both symptomatic as well as asymptomatic pregnant women at regular interval which is beneficial in controlling persistence and recurrence of BV.

\section{Introduction}

The Vagina is a unique environment for bacterial colonization. It is subjected to dramatic changes over course of life time, induced by developmental and hormonal changes ${ }^{(1)}$. The six most common vaginal infections are Bacterial Vaginosis, Candidiasis, Trichomoniasis Vaginitis, Chlamydia Vaginitis, Viral Vaginitis and
Non-infectious Vaginitis ${ }^{(2)}$.

Bacterial Vaginosis (BV) can be described as a shift or disturbance in balance of vaginal microflora, characterized by increase in vaginal $\mathrm{pH}$, reduction in Lactobacillus (Predominately $\mathrm{H}_{2} \mathrm{O}_{2}$ producing species) and increase in other facultative and anaerobic bacteria in number and/or type ${ }^{(3)}$. The normal vaginal microflora consisting of Lactobacillus 
is replaced by over growth of other commensal bacteria like Gardnerella vaginalis, Prevotella species, Fusobacterium species, Porphyromonas species, Peptostreptococcus species ${ }^{(4)}$.

The bacteria involved in BV produce enzymes like mucinase, sialidase and neuraminidase which break down the host cervical and vaginal mucous leading to homogeneous discharge that lacks the cohesion normally induced by mucous. Additional virulence factors cleave IgA and IgM, thereby reducing the host ability to prevent infection ${ }^{(1)}$.

$\mathrm{BV}$ is a spectrum of changes within bacterial community making up the vaginal microbiome that results in a limited number of common clinical symptoms which include, increased thin homogeneous vaginal discharge which is characterized by altered colour (white/grey) and malodour (fishy odour), increase in vaginal $\mathrm{pH}$ which may or may not be associated with burning micturition and itching. The discharge is usually without significant irritation, pain or erythema and the described condition is not associated with leukocyte exudates, redness and swelling. Therefore to distinguish from classical vaginitis, it was termed 'vaginosis' (5) reflects what actually happens during inflammatory process which doesn't connote a common aetiology. The risk factors include douching, antibiotics, usage of IUDs, steroids, new/multiple sex partners, abnormal sugar levels.

Microscopy of vaginal discharge reveals sloughed off vaginal epithelial cells studded with numerous coccobacillary organisms at the margins so that the ridges of vaginal epithelial cells which normally have a sharply defined cell borders become indistinct and stippled. These are known as 'Clue cells', which is characteristic of $\mathrm{BV}$.
Apart from causing unpleasant symptoms, B $\mathrm{V}$ is notorious for setting off an entire array of serious gynaecological and obstetric complications. $\mathrm{BV}$ is an intercurrent disease in pregnancy, associated with complications like miscarriage, chorioamnionitis, premature rupture of membranes, preterm birth and post partum complications like endometritis, wound infection, low birth weight.

Presence of intrauterine infections is one of the important risk factor for preterm labour ${ }^{(6)}$. The immune responses to $\mathrm{BV}$ bacteria ascending into the upper reproductive tract and colonizing the placenta can cause inflammation, with an impact on newborn health ${ }^{(7)}$. Using culture based technique a study showed that the vaginal bacteria can ascend and frequently colonize the preterm placenta during pregnancy ${ }^{(5)}$. The mixture of enzymes produced by organisms associated with BV, break down cervical mucus invade the membranes and produce enzymes which can weaken the membranes, increasing the risk of premature rupture ${ }^{(1)}$. The Gardnerella vaginalis and Prevotella species are high risk factors for intra amniotic infections. BV associated microorganisms and their toxins capable of crossing placenta, are among the major causes of brain injury for foetus ${ }^{(7)}$.

Although BV is associated with numerous health problems like low birth weight (LBW) infants and preventable preterm births ${ }^{(8,9)}$, most of the time it goes asymptomatic and unrecognized.

There are two diagnostic methods to detect BV, Amsel's criteria and Nugent score. Though Nugent method is considered as gold standard diagnostic test, it needs expert for grading, high power microscope and a good laboratory support. The other methods like the culture sensitivity, molecular methods and chromogenic test can be used for diagnosis of 
BV.

However, culture and identification of other bacteria are found to be specific, but insensitive and costly to the laboratory. Other anaerobic bacteria strongly associated with BV such as Mobiluncus species are very difficult to recover by culture.

At the same time normal vaginal Lactobacilli are significantly reduced or absent. As a consequence, clinical diagnosis must rely on methods that identify proportions of bacterial morphotypes in vaginal specimen (12). Quantitative culture showing high concentrations correlates better with $\mathrm{BV}$ in research studies, but culture should not be used for routine diagnosis ${ }^{(1)}$.

An integrated approach based on PCR denaturing gradient gel electrophoresis (PCRDGGE) and real time PCR can be used to study structure and dynamics of bacterial communities in vaginal discharge. Although many different molecular methods have been used in attempts to provide more definitive diagnostic information about $\mathrm{BV}$, it is clear from the plethora of combinations and permutations of possible pathogens analyzed that no single organism or cluster of organisms can identify all cases of $\mathrm{BV}^{(5)}$.

By using Nugent criteria, scores would likely fall in intermediate range and culture or molecular detection results for putative pathogens would be negative, yet the symptoms would still be present ${ }^{(5)}$. And moreover none of these techniques are useful in clinical setting due to complexity and cost.

$\mathrm{BV}$ Blue is a simple and new rapid diagnostic kit for the diagnosis of BV. The detection and measurement of microbial enzyme, in particular sialidase, has potential to be used to rapidly diagnose BV. Prevotella species, Bacteroids species and 20\% of Gardnerella vaginalis have sialidase activity. Most of Mobiluncus species, Peptostreptococcus and Mycoplasma hominis don't show sialidase activity. So, BV caused by Mobiluncus species, Peptostreptococcus and Mycoplasma hominis and about $80 \%$ of Gardnerella vagnilis risk to remain undetected using sialidase method making the test insensitive. With limited available resource there is a great need for proper diagnostic method of $\mathrm{BV}$, which is simple, easy, cost effective, fast and mainly reliable. Hence the sensitivity and specificity of Amsel's criteria is done over Nugent score.

$\mathrm{BV}$ is found all over the globe among the women of reproductive age group. It is an extremely common health problem occurring in $35 \%$ of women attending sexually transmitted infections (STI) clinics, 15\%-20\% of pregnant women and 5\%-15\% of women attending Gynecology $\operatorname{clinics}^{(10,11)}$.

Prevalence of BV is commonly reported from developing countries $(35 \%)$ than developed countries $(24.85 \%)^{(12)}$. However, prevalence of BV ranges from 4\%-64\% depending upon social, geographical and ethnic factors. It is most common in part of Africa and least common in Asia and Europe ${ }^{(6)}$.

Although the prevalence of BV differs widely from country to country within the same region and even within similar population groups its has been estimated to be in the range of $8 \%-75 \%{ }^{(3)}$.

$\mathrm{BV}$ is of special public health concern in India because of the high burden of reproductive and pregnancy-related morbidity.

This study aims at finding out the prevalence of $\mathrm{BV}$ in pregnant women and also comparison between Amsel's criteria and Nugent score method, thereby validating 
accurate diagnostic methods for its detection.

Materials and Methods

\section{Study setting and duration}

The study was conducted among the ANC cases attending ANC Clinics in Department of OBG, at ESIC Medical College and Hospital, Gulbarga from June 2018 till August 2018.

\section{Study design}

It is a prospective, cross-sectional analysis. The study was conducted after receiving written consent from the participants of the study.

\section{Selection criteria}

a) Inclusion criteria: Pregnant women of $2^{\text {nd }}$ and $3^{\text {rd }}$ trimester attending antenatal clinics.

b) Exclusion criteria:

$\mathrm{H} / \mathrm{O}$ bleeding per vagina.

$\mathrm{H} / \mathrm{O}$ diagnosed cases of placenta previa. Cases with $\mathrm{Rh}$ iso-immunization.

Use of local or systemic antibiotics preceding 2 weeks.

Multiple gestations.

Structural uterine abnormality.

\section{Sample collection}

The purpose of the study was explained to the patients. Study proforma was used to get relevant information regarding age, pregnancy status, parity, presence or absence of symptoms and history of sexually transmitted diseases if present.

Two swabs of vaginal discharge were collected from posterior fornix of vagina. One of the swabs was used to determine vaginal $\mathrm{pH}$ and to perform Whiff's test. The other swab was used for wet mount and gram staining.

\section{Amsel's criteria}

$\mathrm{BV}$ is diagnosed if 3 or more of the following criteria are present.

i. Presence of thin, homogenous grey/white discharge.

ii. Vaginal $\mathrm{pH}$ determination:

A swab of discharge was put on to litmus paper to check its acidity. Normal vaginal $\mathrm{pH}$ is slightly acidic being 3.8 to 4.8

$\mathrm{pH}$ greater than 4.5 is suggestive of $\mathrm{BV}$.

iii. Whiff 's test: A drop of vaginal fluid was taken on a glass slide. One drop of $10 \% \mathrm{KOH}$ was added. An intense, putrid, fishy odor is suggestive of BV.

iv. Presence of Clue cells: A drop of vaginal discharge was mixed with a drop of normal saline and it was examined under high power magnification (40*10x magnification). If clue cells constitute $20 \%$ or more of epithelial cells, then it is considered positive.

\section{Nugent score}

Vaginal swab was rolled on a microscopic slide, air dried, heat fixed and then it was gram stained. 10 to 20 high power $(100 * 10 x$ oil immersion) fields were counted under microscope and average was determined according to Nugent score between 0 and 10 based on the following various bacterial morphotypes.

Large gram positive rods: Lactobacillus morphotype

Small gram variable rods: G.vaginalis morphotype

Curved gram variable rods: Mobiluncus spp 
morphotype

Small gram negative rods: Bacteroides spp morphotype

According to table 1, each morphotype was quantified from 1+ to 4+ with regard to number of morphotypes per oil immersion field

Accordingly, the score from

0 to 3 : is considered normal

4 to 6: is considered intermediate (Between normal and $\mathrm{BV}$ vaginal flora)

7 to 10: is consistent with BV

\section{Results and Discussion}

Figure 1: Microscopic findings of vaginal discharge

Out of the 100 samples, 13 cases were diagnosed with BV by Amsel's criteria and 16 cases were diagnosed with BV by Nugent score method. Figure 2 compares the results obtained through Amsel's criteria and Nugent score methods.

Out of 100 cases, 16 were reported to have BV whereas 21 were intermediate score and 63 cases were normal according to Nugent score method (Figure 3).

Out of the positive cases (reported according to Nugent score method), 7 were asymptomatic and 9 presented with symptoms like vaginal discharge, itching and burning micturation. Out of 9 symptomatic cases, 2 reported with the symptoms of burning micturation, 5 reported with vaginal discharge and 2 cases reported with symptoms of vaginal discharge with itching but none of them reported with the symptoms of itching alone. This is depicted in figure 4.

A combination of Lab indices can be used to diagnose BV:

$\mathrm{A}=$ Thin white homogeneous vaginal discharge (which is considered to be typical discharge)

$\mathrm{B}=\mathrm{pH} 4.5$ or more

$\mathrm{C}=$ Positive Whiff test

$\mathrm{D}=$ Presence of Clue cells

Figure 5 represents the various combinations of the Amsel's criteria used for diagnosis of BV (presence of 3 out of 4 criteria indicates positive for $\mathrm{BV}$ )

Prevalence of BV is found to be highest in the age group of $18-23(53.33 \%)$ followed by age group $24-29(40 \%)$ indicating that there is a high incidence of vaginal infections in young individuals of reproductive age group which is depicted in figure 6 .

Out of 16 positive cases, 7 were Primi gravida 9 were multi gravida, indicating that BV is more in multi gravida as per our study $(56.25 \%)$ which is depicted in figure 7.

$3(18.75 \%)$ out of 16 positive cases belonged to $2^{\text {nd }}$ trimester of pregnancy whereas 13 $(81.25 \%)$ out of 16 were reported to be of $3^{\text {rd }}$ trimester in our study which is depicted in figure 8 .

Table 2, 3 and 4 show the comparison between Amsel's criteria V/S Nugent scoring methods for the diagnosis of $\mathrm{BV}$.

The prevalence of BV in this study is $16 \%$, which is in the range of $8 \%-75 \%$ and which is similar to a study conducted at Mysore (Karnataka state) in which the prevalence was reported to be $19 \%$. Various other studies reported prevalence rate to be $44.8 \%, 34 \%{ }^{(4}$, 10).

Prevalence of BV varies from country to country and state to state or region wise within the same country. This difference can 
be attributed to varied geographical features, ethnicity, differences in study populations, economic status, educational background, various vaginal hygiene practices followed among different communities and the methods used for the detection of BV.

The low prevalence rate of $\mathrm{BV}$ in this study can be attributed for less exposure to risk factors like douching and multiple sex partners. Moreover, our study exclusively included only pregnant women whereas the other non pregnant women of reproductive age were not screened for prevalence of $\mathrm{B} V$.

About $50 \%$ of women may not report any symptoms $^{(2,13)}$. In this study about $43.75 \%$ of women did not report any symptoms and $56.25 \%$ of women reported symptoms, with homogeneous white colour discharge - being most commonly reported. However absence of classical discharge doesn't rule out disturbed vaginal flora ${ }^{(11)}$. But the symptoms were underreported by the patients may be because of shyness, embarrassment, privacy concerns or lack of proper knowledge regarding the symptoms.

The proportion of women with BV among age group 18-23 had highest prevalence, which is similar to the results obtained in a study conducted at Hyderabad ${ }^{(14)}$.

Some researchers have previously reported that the condition is most common among younger women, while others have found that the risk of BV increases with age. In India, this may have important implications because women in the age group $18-23$ years range, are at high risk for STI and bad birth outcomes $^{(8)}$.

The current study has statistically significant association between parity of women and prevalence of BV. The women with multi gravida are reported to have higher prevalence of $\mathrm{BV}$ than primi gravida. This can be attributed to the fact that, $\mathrm{BV}$ is technically not sexually transmitted diseases but it is sexually associated condition ${ }^{(10,11)}$.

A total of 100 pregnant women were screened for diagnosis of BV. Among them 16 patients were diagnosed with BV by Nugent scoring, providing a prevalence rate of $16 \%$ and 13 patients were diagnosed with BV by Amsel's criteria providing prevalence rate of $13 \%$.

The sensitivity of Amsel's criteria is $15.38 \%$ and specificity is $88.52 \%$ and that of Nugent score with sensitivity being $23.08 \%$ and specificity $88.52 \%$ in which the Nugent score method is considered to be gold standard.

The positive predictive values of Amsel's v/s Nugent score are $46.15 \%, 56.25 \%$ and negative predictive values are $62.07 \%$, $64.29 \%$ respectively.

These results are lower than the results obtained with a similar study conducted at Ethiopia, with sensitivity and specificity of Amsel's v/s Nugent being 85.7\%, 91.3\% respectively ${ }^{(12)}$. This difference in sensitivity and specificity may be due to difference of study population and lower prevalence of BV.

The cases with Candida infection had symptoms similar to that of BV which were reported to be negative for $\mathrm{BV}$. And importantly, both symptomatic and asymptomatic cases were screened for the prevalence of $\mathrm{BV}$, where $23.07 \%$ of symptomatic cases were diagnosed with BV and $11.47 \%$ of asymptomatic cases were reported to have $\mathrm{BV}$. 
Table.1 Nugent scoring depending on morphotypes of different microorganisms

\begin{tabular}{|l|c|c|c|c|c|}
\hline \multirow{2}{*}{ Morphology } & \multicolumn{4}{|c|}{ Number of morphotypes seen per oil power field } \\
\cline { 2 - 5 } & None & $\begin{array}{l}\text { Less than or } \\
\text { equal to 1 }\end{array}$ & $1-5$ & $5-30$ & $>30$ \\
\hline Lactobacillus & 4 & 3 & 2 & 1 & 0 \\
\hline G. vaginalis / Bacteroides & 0 & 1 & 2 & 3 & 4 \\
\hline Mobiluncus & 0 & 1 & 2 & 3 & 4 \\
\hline
\end{tabular}

Table. 2 Number of symptomatic \& asymptomatic antenatal cases with positive and negative results by Amsel's criteria (Sensitivity, specificity, PPV \& NPV of Amsel's criteria)

\begin{tabular}{|l|l|l|l|l|l|l|}
\hline Amsel's criteria & Positive & Negative & SN & SP & PPV & NPV \\
\hline Symptomatic & 6 & 33 & & & & \\
\hline Asymptomatic & 7 & 54 & 15.38 & 88.52 & 46.15 & 62.07 \\
\hline TOTAL & 13 & 87 & & & & \\
\hline
\end{tabular}

SN-sensitivity; SP-specificity; PPV-positive predictive value; NPV-negative predictive value

Table.3 Number of symptomatic \& asymptomatic antenatal cases with positive and negative results by nugent scoring (Sensitivity, specificity, PPV \& NPV of Nugent scoring)

\begin{tabular}{|l|c|l|l|l|l|l|}
\hline Nugent Scoring & Positive & Negative & SN & SP & PPV & NPV \\
\hline Symptomatic & 9 & 30 & & & & \\
\hline Asymptomatic & 7 & 54 & 23.08 & 88.52 & 56.25 & 64.29 \\
\hline TOTAL & 16 & 84 & & & & \\
\hline
\end{tabular}

SN-sensitivity; SP-specificity; PPV-positive predictive value; NPV-negative predictive value

Table.4 Comparison of Amsel's Criteria and Nugent scoring methods for diagnosis of BV

\begin{tabular}{|l|l|l|c|c|}
\hline \multicolumn{3}{|l}{ Nugent scoring } & p-value \\
\hline \multirow{2}{*}{$\begin{array}{l}\text { Amsel's } \\
\text { criteria }\end{array}$} & POSITIVE & POSITIVE & NEGATIVE & \multirow{2}{*}{$<0.00001$} \\
\cline { 2 - 4 } & NEGATIVE & 5 & 2 & \\
\hline & TOTAL & 16 & 84 & \\
\hline
\end{tabular}

In order to verify the statistical significance of this study, chi square test was applied to the results comparing Amsel's criteria and Nugent score methods. The chi square statistic is 52.3441 and the p-value is $<0.00001$ (where the result is significant at $\mathrm{p}<0.05$ ). In other words, the above readings are statistically significant implying, Nugent score is more sensitive and specific than Amsel's criteria. The sensitivity and positive predictive value of Nugent score is better than that of Amsel's, making 'Nugent score' a better diagnostic test for BV. 
Fig.1 Microscopic findings
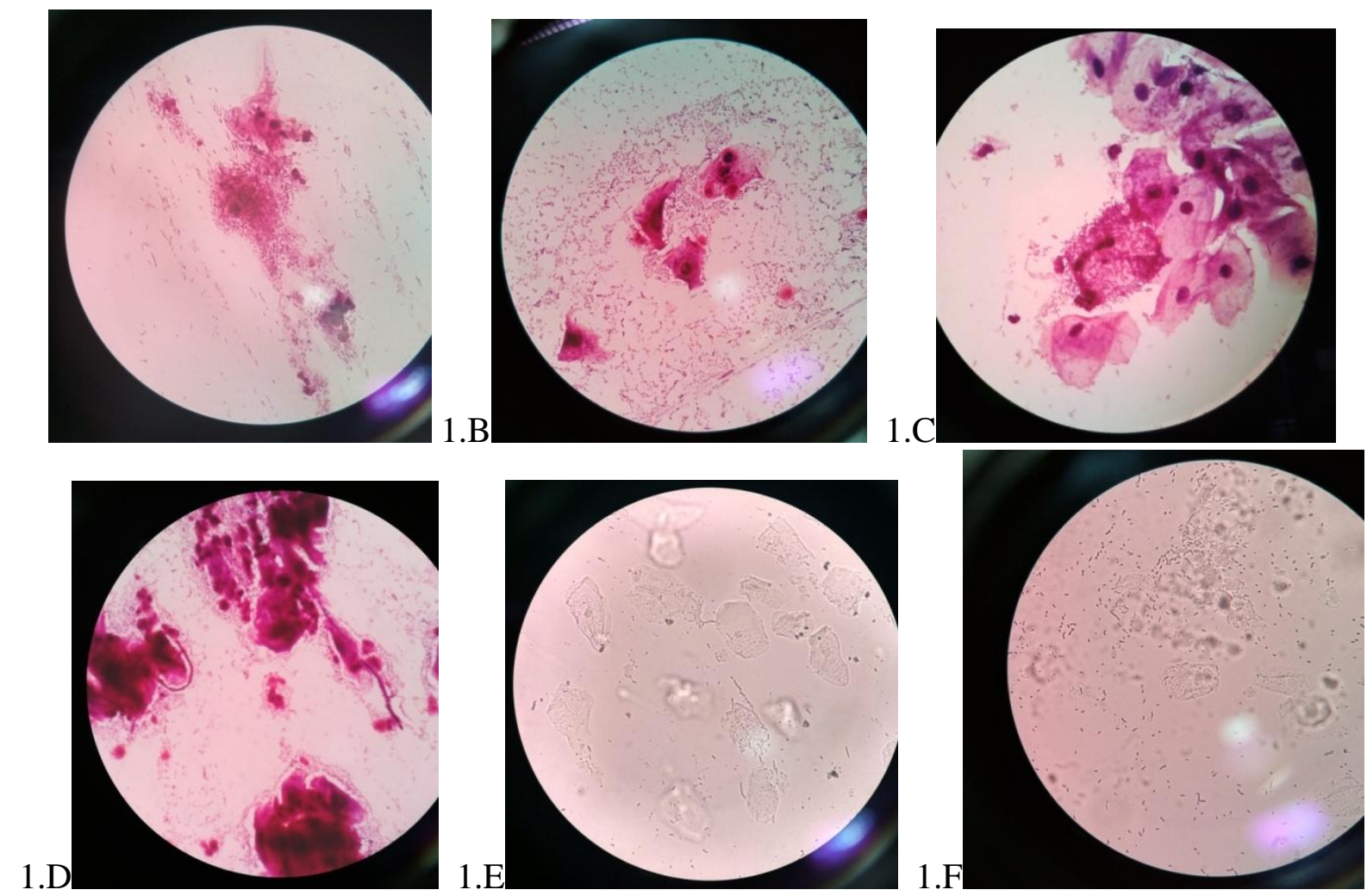

Figure 1.A, 1.B and 1.C: Bacterial vaginosis on gram staining, 1-1.5 $\mu \mathrm{m}$, gram negative rods with epithelial cells (under oil immersion)

Figure 1.D BV on gram stain 1-1.5 $\mu \mathrm{m}$, gram negative rods with epithelial cells associated with Candidiasis presence of 4-6 $\mu \mathrm{m}$ oval, budding yeast cells along with pseudohypae

Figure 1.E and 1.F Clue cells in saline wet mount preparation, epithelial cells studded with $1-1.5 \mu \mathrm{m}$ bacilli

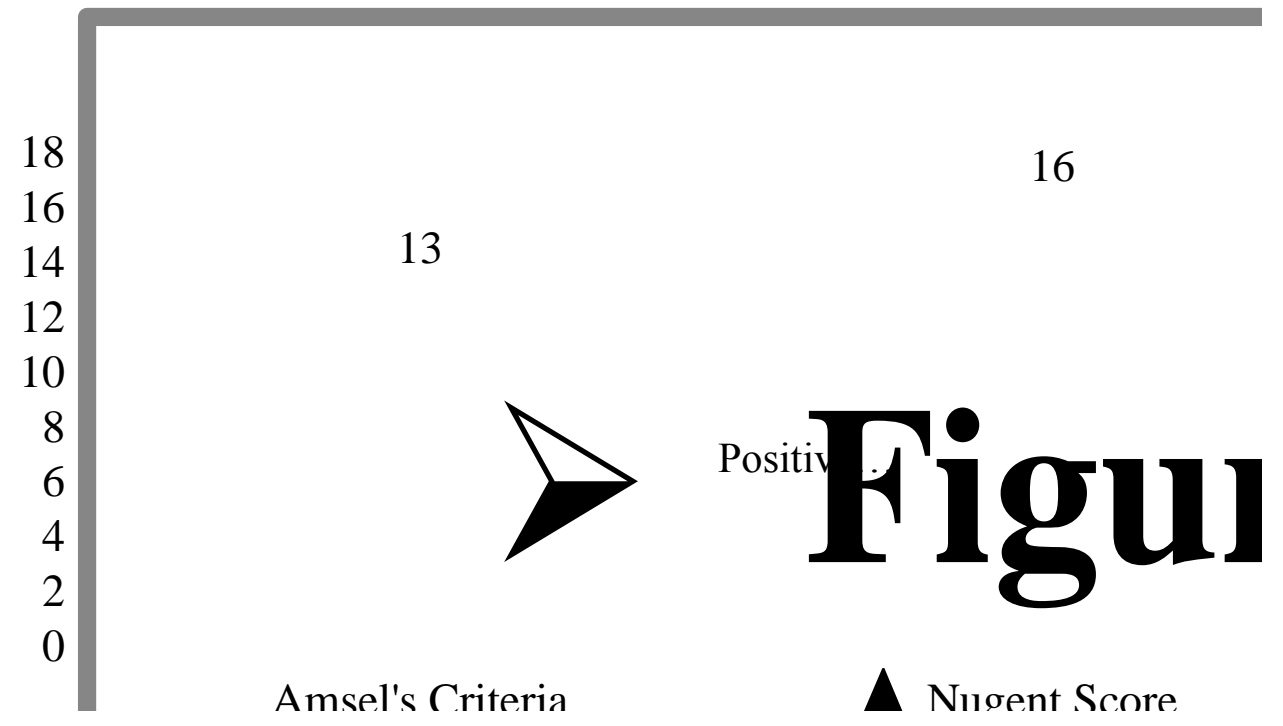


Figure 3: Results obtained through Nugent score method

16

$\begin{array}{lll}21 & 63 & \text { Normal } \\ & 3) \\ & \text { Intermeı } \\ & (4-6)\end{array}$
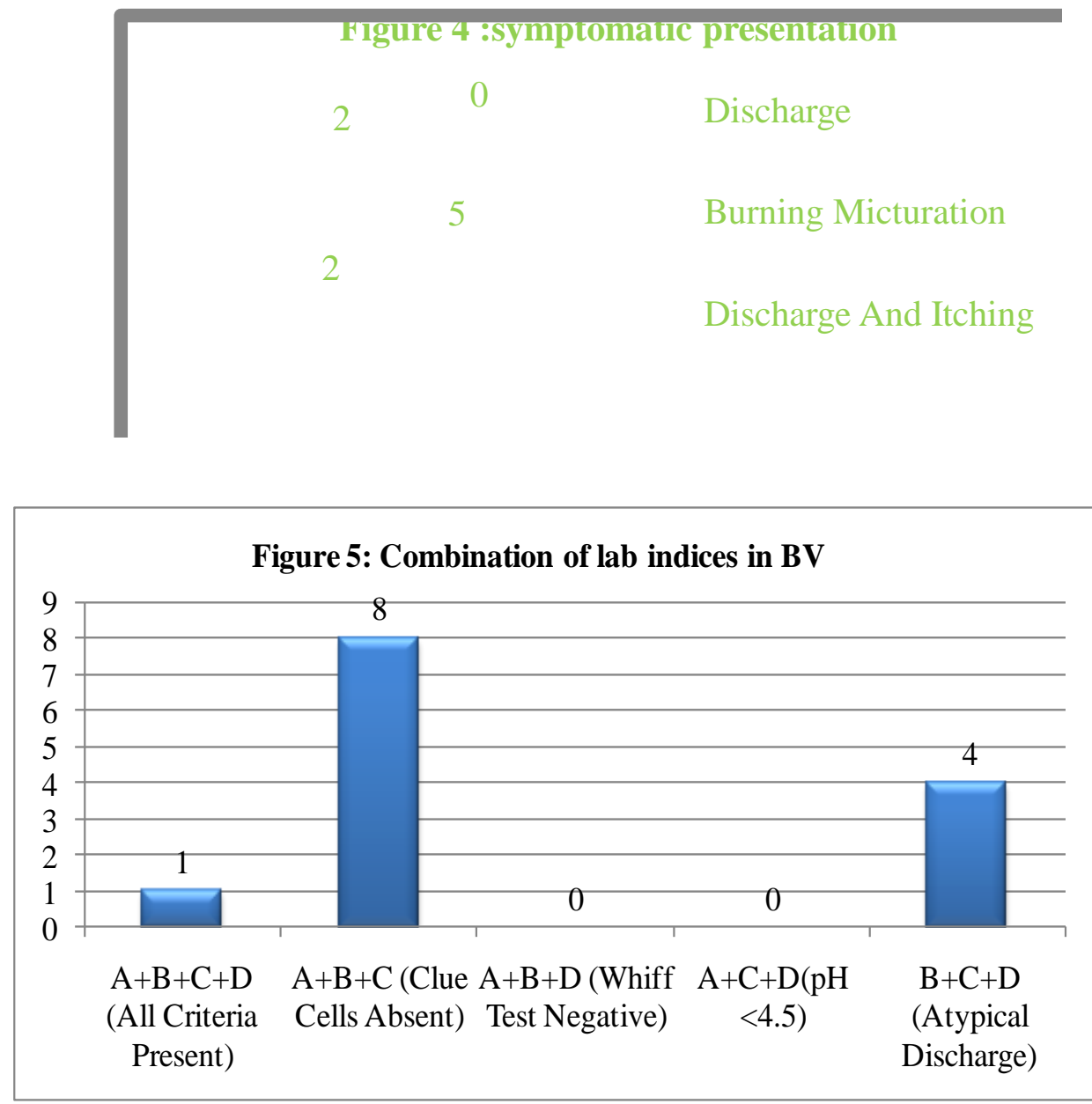

Out of 13 cases, 1 case (7.7\%) satisfied all the four criteria of Amsel's. 4 cases (30.76\%) had atypical discharge. 8 out of 13 cases $(61.53 \%)$ reported with typical discharge along with positive Whiff test and vaginal $\mathrm{pH}$ with 4.5 or more. None of the cases reported negative for Whiff test and $\mathrm{pH}$ less than 4.5, whereas, Clue cells were present in only 5 out of 13 cases $(38.64 \%)$ 

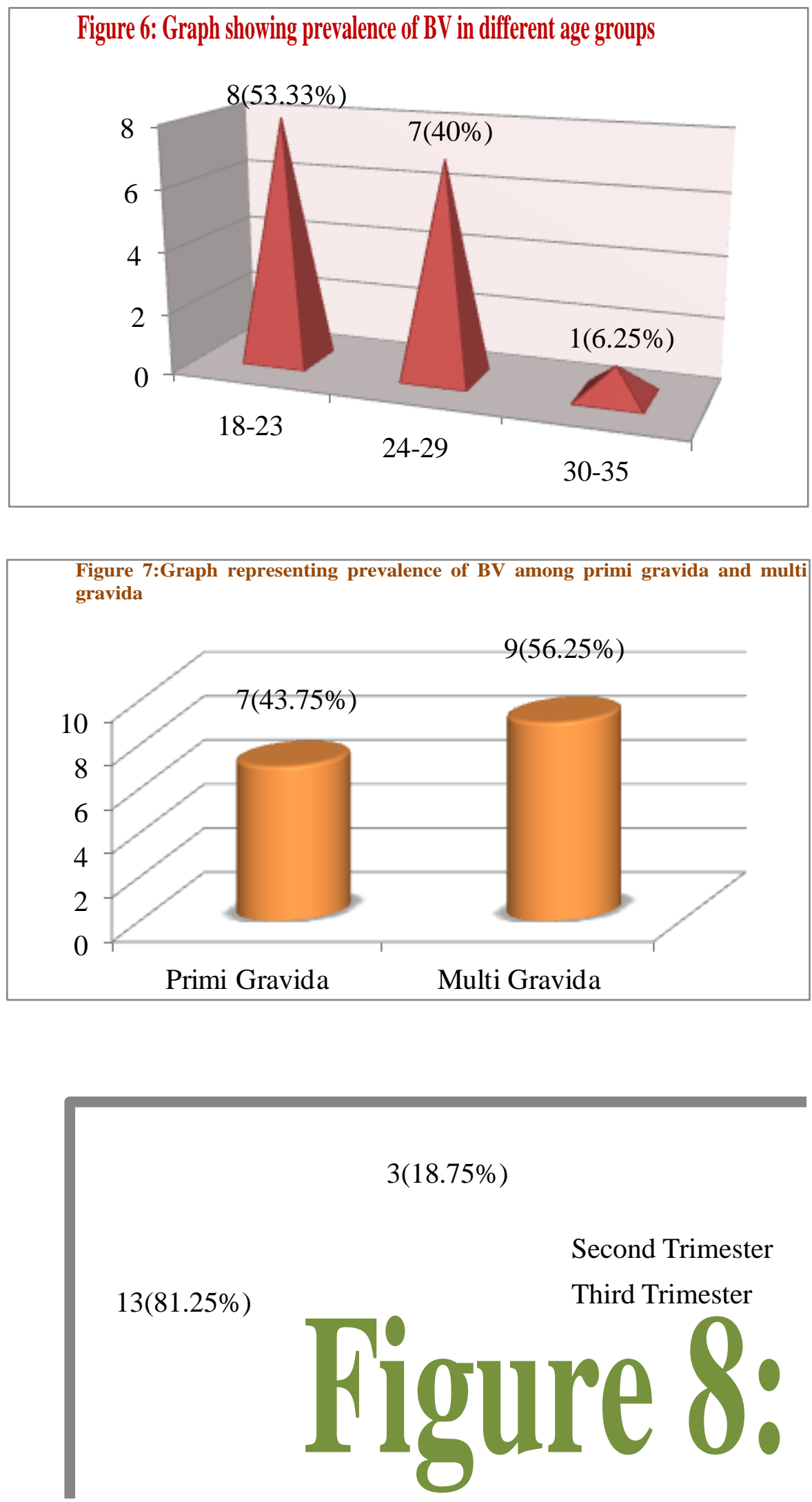
Since the symptoms were underreported in most of the asymptomatic cases and there was overlapping of similar BV symptoms among patients with Candida infection; may have accounted for the low sensitivity and specificity of the diagnostic tests when compared to other similar studies.

Amsel's and Nugent's methods remain the most practical, viable and economical options for diagnosing bacterial vaginosis, especially in developing countries. Bacterial vaginosis is often misdiagnosed using clinical criteria alone because the components are subjective and depend on the acuity of the clinician and the availability of equipment ${ }^{(10)}$.

The decrease in sensitivity of Whiff test may attribute to subjective nature of the test due to sensation ability of the person doing the test. The other factor may be absence or presence of low number of amine producing abnormal microorganism $^{(12)}$.

Clue cells were absent in 8 out of 13 cases of BV(diagnosed by Amsel' s criteria). In a similar study conducted at Shadan Institute of Medical Science, Hyderabad, India, Clue cells were absent in $10.3 \%$ of cases ${ }^{(14)}$. So, as compared to Amsel's criteria, Nugent score allows assessment of alteration in vaginal flora as a continuum rather than dichotomy ${ }^{(10)}$.

6 out of 21 women with intermediate BV harbored a huge number of Lactobacilli along with plenty of other BV microflora, which is an atypical result. Researchers suggest that in some women growth of BV related pathogens can occur prior to decline of vaginal Lactobacilli ${ }^{(7)}$. $32 \%$ of patients with an intermediate score will proceed to BV and 30\% to normal flora. Many authors feel that an intermediate score should be included as abnormal given the high rate of transition to $\mathrm{BV}$. The decision to re-check or treat is based on the clinical risk of proceeding to $\mathrm{BV}^{(11)}$.

Interestingly 9 out of 100 women were affected with Candidiasis, 2 were affected with Streptococcus species. An association of BV with Candidiasis was seen in 2 cases.

\section{Acknowledgements}

We acknowledge STS Program of ICMR under which the research was carried out. A special thanks to Dr. Nagarkar Rajhans Kishanrao for his constant support and guidance throughout the study. We are thankful to Dr. Parandekar Prashant K, Professor and Head of Department of Microbiology, who provided expertise that greatly assisted the research. We are also grateful to Dr. Supriya Tile for her help during the research. We are also immensely grateful to our Dean Dr. A. L. Nagaraja and Academic Registrar Dr. H. S. Kadlimatti for their support. We have to express our appreciation to Dr. Anirudh for his help while writing the results. Heartfelt thanks to my parents for their support and encouragement. We also want to thank each and everyone who directly or indirectly helped us during our research.

\section{References}

1. Phillip E. Hay, Bacterial Vaginosis as a Mixed Infection. Polymicrobial diseases. Washington (DC): American Society of Microbiology press 2002

2. Devapriya F, Mawahib A. Albiate, Jayadevan Sreedharan, Jayakumary Muttappallymyalil, Elsheba Mathew. Micro-biota of vaginal infection among women in the reproductive age group: A hospital-based study, Gulf Medical Journal, ASM 2012; 1(S1): S64-S71.

3. Adane Bitew, Yeshiwork Abebaw, Delayehu Bekele, and Amete Mihret Prevalence of bacterial vaginosis and associated risk factors among women complaining of genital tract infection, International Journal of Microbiology Volume 2017, Article ID 4919404.

4. Akshita R. Seth, Chaitra S., Vaishnavi S., Sharath Chandra G. R Prevalence of bacterial vaginosis in females in the reproductive age group in Kadur, Karnataka, India, Int J Reprod, Contracept, Obstet and Gynecol, 2017 
Nov;6(11):4863-4865.

5. Andrew B. Onderdonk, Mary L. Delaney, Raina N. Fichorova. The human microbiome during bacterial vaginosis, American Society for Microbiology, April 2016 Volume 29, Number 2, Page 223-238.

6. Chembetei Kavitha Kiran, Jithendra Kandati, Munilakshmi Ponugoti. Prevalence of bacterial vaginosis in preterm and term labour: a one year study, Int J Reprod, Contracept, Obstet and Gynecol. 2017 June; 6 (6): 22922296.

7. Yevgeniy Turovskiy, Katia Sutyak Noll, and Michael L. Chikindas The etiology of bacterial vaginosis, Journal of Applied Microbiology 2011 May; 110(5): 11051128.

8. $\mathrm{P}$ Madhivanan, $\mathrm{K}$ Krupp, V Chandrasekaran, C Karat, A Arun, CR Cohen, AL Reingold, and JD Klausner. Prevalence and correlates of bacterial vaginosis among young women of reproductive age in Mysore, India, Indian Journal of Medical Microbiology, 2008; 26(2): 132-137.

9. J. Nzomo, P. Waiyaki, R. Waihenya, Bacterial vaginosis and correlates in women of reproductive age in Thika, Kenya, Advances in Microbiology, 2013: (3) 249-254.

10. Gomty Mahajan, Amita Mahajan.
Comparison of different diagnostic methods of bacterial vaginosis - Amsel's vs Neugent, International Journal of Current Microbiology and Applied Sciences ISSN: 2319-7706 Volume 6 Number 5 (2017) pp. 1442-1448.

11. D Money. The laboratory diagnosis of bacterial vaginosis. Can Journal of Infectious Diseases and Medical Microbiology 2005; 16(2): 77-79.

12. ZeMenu MengiStie, YiMtubeZinaSh WoldeaManuel, Daniel Asrat, Mahlet Yigere $\mathrm{Mu}$. Comparison of clinical and gram stain diagnosis methods of bacterial vaginosis among pregnant women in Ethiopia, Journal of Clinical and Diagnostic Research. 2013 Dec, Vol7(12): 2701-2703.

13. Joscelyn N. Hoffmann, Hannah M. You, E. C. Hedberg, Jeanne A. Jordan, and Martha K. McClintock Prevalence of bacterial vaginosis and candida among postmenopausal women in the United States, Journals of Gerontology, Series B: Psychological Sciences and Social Sciences, 69(8).

14. Sarada Tiyyagura, Madhuri Taranikanti, Swathi Ala, Dinesh Raj Mathur, Bacterial vaginosis in Indian women in the reproductive age group, International Journal of Biomedical Research, Ijbr 3[08] [2012].

\section{How to cite this article:}

Rajesh Tile, Nisarga B. Kunte, Nagarkar Rajhans Kishanrao, Supriya Jamkhandi and Parandekar Prashant, K. 2019. Microscopy, is that an Effective Diagnostic Tool for Bacterial Vaginosis? Int.J.Curr.Microbiol.App.Sci. 8(06): 96-107. doi: https://doi.org/10.20546/ijcmas.2019.806.013 